\title{
RHYTHM IN THE GREENLAND GLACIAL ANTICYCLONE
}

\section{WILLIAM H. HOBBS}

The German and the British Greenland expeditions of 1930-31 gave to the world the first continuous records of meteorological conditions within the cold interior region of the Greenland glacial articyclone [see 1 of "References" at end of paper]. Of the two expeditions the former was much the more important, for the reason that its station was manned by experienced and very competent meteorologists who were provided with some aerological equipment, and it was in operation [2] continuously for slightly more than a year (August 1, 1930, to August 8, 1931).

The observations made at Mid-Ice have never been adequately discussed in print, for after the death of the leader in the winter of 1930 the direction of the expedition was taken over by the strong Hitler party-man, KURT WEGENER, who refused permission to Dr. GEORGI, the director of the station, to treat his observations in the expedition reports. By use of a remarkable meteorological diagram, of which no parallel exists, GEORGI was able to make it tell its own story. This diagram, four feet in length, on a smaller scale and with English names and additional marginal material, has been reproduced in the upper part of Figure 1.

On inspection of this remarkable diagram it will at once become apparent that within the cold interior region air-temperature, nebulosity, and wind-force all vary together in the most striking correspondence. To a very large extent this is true also of air-pressure, which will surprise meteorologists who are accustomed to associate rise of pressure with fall of atr-temperature and vice versa. There are, however, some exceptions shown in the chart--a notable one in March. observers at the University of Michigan weather-stations on the Greenland west coast have long been familiar with this unusual relationship between pressure and temperature, for about as many surges from the interior come with rising as with falling barometer, and certain of each of these classes are associated with rising air temperatures--the foehn effect.

The diagram betrays also an approach to periodicity, a sort of rhythm best brought out in the temperature-diagrams. There is a longer period which averages 23 days, and a shorter one of about six and a half days. Making use of maxima of temperature, these periods have been indicated in the margin. These rises in temperature are closely associated with an increase of the cloud-cover with the response a very sudden one. Outgoing radiation is apparently screened out by the cover so as to produce this effect. It is so sharp that it is registered almost at once in the body-reaction.

By plotting the daily air-temperatures recorded at the British Ice Cap Station [3] and comparing them with those observed on the same dates at Mid-Ice, exactly the same periods are observed, though the two stations are separated by more than 250 nautical, or 280 statute, miles and by $4^{\circ}$ of latitude (see lower part Fig. 1). This can only be interpreted to indicate that the glacial anticyclone of Greenland operates very much as a unit, rather than in separated component parts which are not sonchronized. A quite similar comparison made between the interior Mid-Ice Station and West Station, which is in the same latitude but some 200 odd miles farther west and on the ice-cap outside the interior zone, reveals closely related but not identical periods (see lower part Fig. 1) [4]. This was to be expected since all winds blow from the interior station to this exterior one. There snould be a lag of some hours for related changes at the West Station, but these would probably not be apparent in a diagram of this scale.

The most reliable part of the diagrams for the purpose of revealing the rhythm is that corresponding to the time when the Sun is below the horizon or at a small angle above it. At such time any mere daily variations are very small, and no place upon our planet except the unexplored part of the Antarctic Continent is in any way comparable. The surface is formed of pure white snow which reflects at least 80 per cent of any incoming radiation, and the sun is too low to send any except much refracted rays. The ends of the diagram for the summer months make this strikingly apparent.

Since the outgoing surges from central Greenland become the strong westerly storms of the eastern coast, it is of the greatest interest and importance to compare the times when they start with the arrival of stormy weather in northwestern Europe. It would be vastly important also to see what correspondence there is, if any, of these times with the arrival at Greenland, or passage by, of cyclones from the west. For this purpose the synoptic weather-charts of 1930-31 are much too unreliable [5]. 


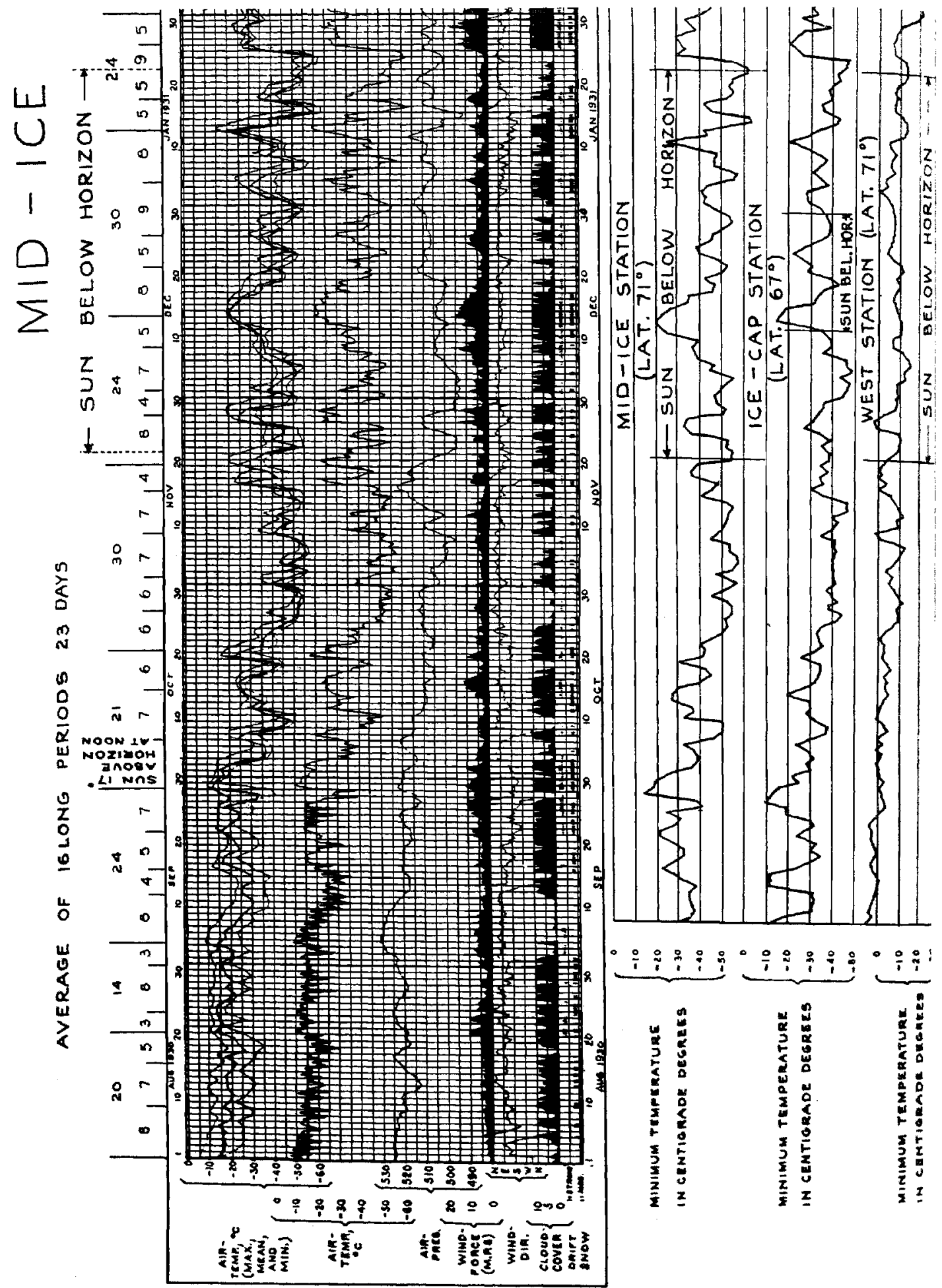




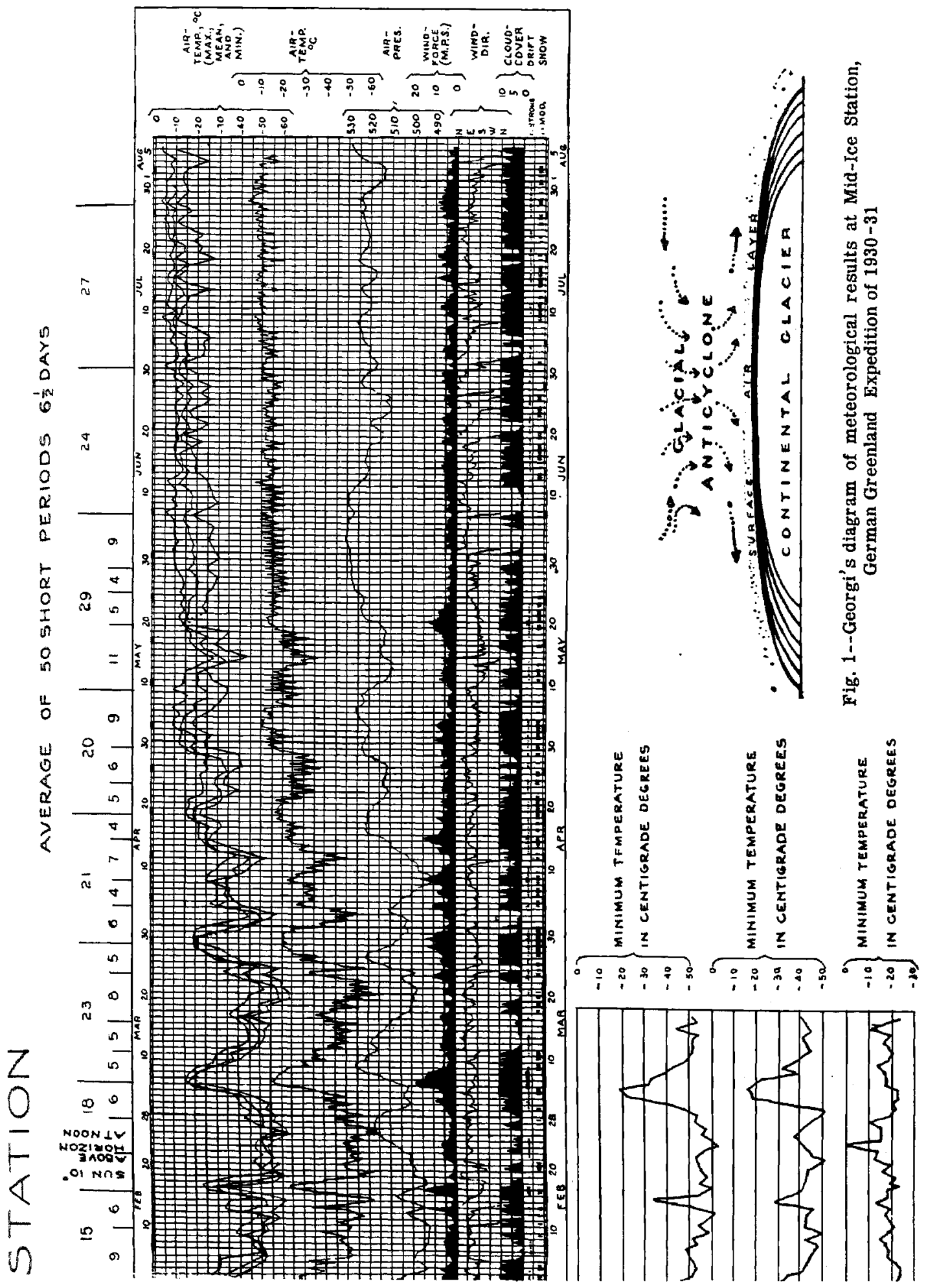


It is to be expected that one or more permanent mid-Greenland weather-stations will, as soon as is practicable, be set up to forecast the weather of northwestern Europe. One should be located in as high a latitude as practicable in order to have the period of the Sun's absence as prolonged as possible, and it should be provided with radiosonde equipment. When such station or stations are available, it is to be hoped that synoptic weather-charts will take account of observed facts for the Greenland Region.

\title{
References
}

[1] See J. Geol., จ. 52, pp. 84-91, 1944.

2] It has become evident that this station was maintained primarily to secure important data to be later used in forecasting the weather of Europe in time of war. Though a line of precise levels was run from the west coast to the central weather-station of Mid-Ice, the results, which would be of utmost importance in solving the meteorological problems and especially in forecasting, still remain a German military secret. See K. WEICKEN, Wiss. Ergebn. Deutsch. Grönl.-Exped, Alfred Wegener, 1929 u. 1930-31, v. 5, pp. 1-4, Leipzig, 1940.

[3] S. T. A. MIRRLEES, Met. Office, Air Min., Geophys. Mem., No. 61, pp. 48-54, 1934.

4] R. HOLzAPFEL, Wiss. Ergebn. Deutsch. Grönl.-Exped. Alfred Wegener 1929 u. 1930-31, v. 4, Part I, pp. 387-530, 1935.

[5] See W. H. HOBBS, J. Geol., v. 52, pp. 73-96, 1944; also W. H. HOBBS and R. L. BELKNAP, Trans. Amer. Geophys. Union, pp. 482-490, 1944.

Department of Geology, University of Michigan, Ann Arbor, Michigan

\section{INTERNATIONAL CLOUD-NOMENCIATURE AND CODING}

\author{
Charles F. Brooks
}

\section{History}

Since LUKE HOWARD, in 1803, proposed a cloud-nomenclature that was simple enough for the needs of meteorology at that time, there has been an international nomenclature, based essentially on HOWARD, that has grown with the increasing detail of meteorological observations and forecasting. HOWARD distinguished between ice-clouds and liquid clouds, between heaped-up and layer clouds, and between rain-clouds and others.

As HOWARD'S nomenclature was expanded and modified, international diversity was natural yet confusing. So, in 1879, HILDEBRANDSSON published a cloud-atlas; and in 1887 HILDEBRANDSSON and ABERCROMBY published a classification of cloud-types they had chosen almost wholly from nomenclatures then in use. All were compounded of HOWARD'S four fundamental types (cirrus, stratus, cumulus, and nimbus). They chose them with an eye to the needs of practical meteorology and to the least disturbance of existing cloud-nomenclatures. [For history of this subject, see 1 of "References" at end of paper.]

These cloud names received international sanction in 1891, and, thanks to TIESSERENC DE BORT, discoverer of the stratosphere, the first international cloud-atlas, of 27 colored plates with text in French, English, and German, was published in 1896. Embodying slight changes made in 1905 , a second edition was published in 1910 .

The requirements of the polar-front theory and air-mass analysis for a more detailed claudnomenclature and a redefinition of some of the terms to bring out distinctions of prime importance synoptically were activated by the apoointment, in 1921, of the International Commission for the Study of Clouds. A provisional "Observers' atlas" appeared in 1928 and the final "International, atlas of clouds and states of the sky," abridged edition, in 1931, and, in 1932, "I: General atlas" (including 174 photographic plates, 31 of them colored), and "II: Atlas of tropical clouds" (in French only), the publication of which at a moderate price was made possible by the generosity of the Patxot Institute of Catalonia. The third and fourth volumes, "Atlas of special clouds" and "Physical processes involved in the formation of clouds" [2], have not yet appeared.

The present International Classification compared with the old

While retaining nine of the ten long-standard names, and adopting "nimbostratus" as a substitute for, but not the exact equivalent of, the ambiguous "nimbus", a more detalled nomenclature 